\title{
ABORDAGEM DA SEXUALIDADE HUMANA EM LIVRO DIDÁTICO DE CIÊNCIAS - DESVELANDO OS BASTIDORES DE UMA PROPOSTA.
}

\section{APPROACH OF HUMAN SEXUALITY IN SCIENCE TEXBOOKS - REVEALING THE BACKSTAGE OF A PROPOSAL}

\author{
Margarida Carvalho de Santana ${ }^{1}$, Mônica de Cássia Vieira Waldhelm² \\ ${ }^{1}$ Faculdade de Filosofia Santa Dorotéia - Nova Friburgo/RJ. santana.margarida@ yahoo.com.br \\ ${ }^{2}$ Mestrado Profissional em Ensino de Ciências e Matemática e Especialização em Educação Tecnológica \\ do CEFET/RJ-UAB. mwaldhelm@gmail.com
}

\section{Resumo}

Neste texto, professoras, com longa militância em sala de aula, relatam o processo e os desafios ao assumirem se tornarem autoras de livro didático. Após breves reflexões sobre as questões referentes ao livro didático e ao currículo, as autoras revelam os bastidores do processo de produção da proposta: estudos, pesquisas, reuniões e mais os embates internos e as pressões externas. Optam por destacar a abordagem da sexualidade humana e suas interfaces com a ciência e a saúde; os cuidados que se impõem ao falar do corpo e da sexualidade em material didático, cujos textos e imagens não reforcem crenças subjetivas, tabus e preconceitos, e nem disseminem informações errôneas, mas sim, construam conhecimentos que gerem a prática do cuidado com o corpo associado à promoção da saúde e à vivência prazerosa e responsável da sexualidade.

Palavras-chave: livro didático - sexualidade - currículo - professores - ciências

\begin{abstract}
In this article, teachers with a long classroom militancy, describe the process and challenges to become authors of textbooks. After brief reflections on issues related to textbooks and curriculum, the authors show the background of the production process: studies, research, meetings and even internal conflicts and external pressures. They choose to highlight their approach in human sexuality and its interfaces with science and health, the care that is necessary when speaking of the body and sexuality in educational materials, where texts and images should not strengthen subjective beliefs, like taboos and prejudices, and do not spread erroneous information, but build knowledge that generates the practice of caring the body associated to the promotion of health and a pleasant and responsible sexual living.
\end{abstract}

Keywords: textbook - sexuality - curriculum - teachers - science 
Este texto resultou de um convite para que socializássemos nossa experiência de professoras que se tornaram autoras de livros didáticos de circulação nacional. Uma tarefa instigante! Porém, o que priorizar? O processo da composição da equipe? Ou o da seleção dos conteúdos e da metodologia? Ao relembrar os embates internos e as pressões externas na produção da coleção, optamos em abordar o tema que demandou maior discussão devido à relação entre saber científico e questões de natureza ética e social, dentre outras: a sexualidade. Das múltiplas e variadas experiências vividas, nesta década em que atuamos no papel de autoras de livros didáticos, a tarefa de abordar a sexualidade humana neste tipo de material mostrou-se a mais desafiadora. Além disso, entendemos que este tema, por sua dimensão plural, seria do interesse de docentespesquisadores cujos trabalhos apresentam interface entre ensino, saúde e ambiente. Lembramos que, não é objetivo deste relato traçar um histórico do livro didático no ensino brasileiro. No entanto, pontualmente, faremos alguns recortes para contextualizar historicamente o papel deste recurso no trabalho docente bem como o da sexualidade nos currículos e livros de ciências. Nosso interesse principal é desvelar (e revelar) os bastidores do processo de produção de um livro didático, no que tange à abordagem da sexualidade humana. Esclarecemos, de antemão, que neste trabalho mobilizamos ferramentas cognitivas, experiências, impressões, concepções, crenças, representações, expectativas, valores, certezas e incertezas que compõem nossa identidade de

professoras-pesquisadoras-autoras de livros didáticos. Assim, assumimos explicitamente as implicações que esta identidade trouxe às nossas análises e discurso.

\section{O livro didático}

Iniciamos esta conversa com a reflexão sobre a função social da escola e do material didático e o conteúdo que veicula. Ao buscar referências em Foucault, dentre outros, temos que considerar que a escola ocupa um locus no qual se apresentam outros procedimentos tão ou mais eficazes que seus instrumentos didáticos na transmissão de valores, tais como: a hierarquia, a autoridade, crenças subjetivas, avaliações, promoções, divisões acadêmicas do conhecimento e do trabalho pedagógico. E nossa vivência nos informa ser a escola, também, um espaço de criatividade e reformulações. É neste contexto que destacamos para este trabalho o livro didático. 
Muitos trabalhos sobre o livro didático têm sido realizados, o que se justifica por ser ele ainda o instrumento mais significativo em uso nas salas de aula, não só como recurso de apoio, mas muitas vezes norteando todo o trabalho pedagógico. Por vezes a distorção de papéis é tal que o professor é "adotado" pelo livro. Obras como as organizadas por Fracalanza e Megid Neto (2006) mostram muito bem isto. O livro didático faz parte do conjunto de objetos envolvidos cotidianamente nas atividades escolares, nos diferentes níveis. Dentre esses objetos, do giz ao computador, o que provavelmente tem maior impacto na aprendizagem, na maior parte das escolas brasileiras, é o livro didático, por seu uso sistemático. Sabemos o quanto o livro se reveste de um status de verdade para alunos e professores e tem o poder de influenciar significativamente a dinâmica da sala de aula. Assim, as atividades sugeridas, a abordagem dos conteúdos, o tipo de discurso, figuras utilizadas, exercícios propostos etc. são fundamentais no ensino que efetivamente se dará, favorecendo a interatividade ou a mera "transmissão" de conteúdos.

Vale ainda lembrar que, tendo em vista o baixo poder aquisitivo das camadas populares e a alta taxa de evasão e repetência, o livro didático pode representar um dos poucos textos com os quais os alunos vão ter contato. Percebe-se, portanto, que a problemática do livro didático está inserida em um contexto mais amplo, que perpassa o sistema educacional e envolve estruturas globais da sociedade, como o Estado, o mercado e a indústria cultural. Neste contexto, é oportuno destacar a importância do livro didático no século XX, em particular a partir da década de 1970, quando registramos a participação direta do Estado na definição de uma política educacional com apresentação de propostas curriculares, com a publicação de parâmetros curriculares e guias que vão orientar a produção do livro didático. Também é relevante citar a instituição do Programa Nacional do Livro Didático - PNLD, que possibilitou novos autores a se empenharem na tarefa de escrever livros didáticos.

Ao discutir quaisquer aspectos do livro didático é necessário fazê-lo na perspectiva da reflexão sobre o ensino e a aprendizagem, visto que esse processo acontece mediado, de maneira significativa, por dois instrumentos: o livro didático e o currículo. Um estudo de Megid Neto e Teixeira (2006) buscou, dentre outros objetivos, analisar o impacto sobre a pesquisa e ensino de Ciências no Brasil, do crescimento das investigações na área de Educação em Ciências constatado por eles em seu levantamento. Segundo esses pesquisadores, a produção acadêmica ligada à área de 
Ensino de Ciências, na forma de dissertações e teses, existe desde o início da década de 1970. Em pouco mais de 30 anos se consolidou, tornando-se um campo bastante relevante no âmbito da pesquisa em Educação no país. Temos também hoje, uma ampla produção acadêmica e científica, constantemente divulgada em encontros, revistas e outros meios. Entretanto, como atentam Santos e Greca (2006), ainda prevalecem roteiros tradicionais de ensino que se consolidam em livros didáticos que conservam, em essência, as mesmas seqüências lineares e fragmentadas de conteúdos, mesmo que sempre enriquecidos com novas ilustrações que lhes dão certo status de atualização. Criticam, também, o uso didático cada vez maior de apostilas produzidas no âmbito dos "cursinhos" preparatórios para vestibulares, que são adotadas também dentro de escolas conveniadas. Neste tipo de material didático os conhecimentos propostos são ainda mais fragmentados e a aprendizagem vira sinônimo de capacidade de resolver repetidamente exercícios propostos para os mesmos itens de conteúdo, concebidos de forma linear e desarticulada.

Que tipo de conteúdos deve abordar um currículo de ciências que alfabetize cientificamente e prepare para a cidadania? Para Hodson (1994), os alunos devem aprender ciência, aprender a fazer ciência e aprender sobre a ciência. Na prática, o currículo de Ciências, do sexto ao nono ano do Ensino Fundamental, que vem norteando o ensino brasileiro atualmente ainda mantém uma abordagem estanque e fragmentada dos conteúdos, predominantemente do tipo factual e conceitual. Nesse currículo fragmentado, os conteúdos de Ciências costumam serem assim divididos: no sexto ano: ar, água e solo; no sétimo: seres vivos; no oitavo: corpo humano e no nono: Química e Física. Em geral, os conteúdos são estudados de forma desconectada entre si e com a realidade do aluno. Percebe-se também uma valorização dos conteúdos da Biologia nesse currículo, o que provavelmente se dá pelo fato da maioria dos professores de Ciências das séries em questão ter formação nessa área e nela apresentar maior segurança conceitual. A maior parte dos livros didáticos existentes no mercado editorial ratifica essa organização estanque, fragmentada e "biologizante" do currículo de Ciências. Quando autores de livros ousam propor uma coleção com abordagem menos linear e fragmentada, rompendo com a organização tradicional, têm pouco sucesso na adoção pela maioria dos professores, que parecem se sentirem mais seguros em utilizar livros da chamada linha tradicional. 
Cabe ressaltar, que não estamos, sob hipótese alguma, desconsiderando as características da chamada Sociedade da Informação e Conhecimento, produzida sob um acelerado ritmo de inovações tecnológicas e convergência de informação e comunicação e assim superestimar o papel do livro didático em relação a outros instrumentos para o trabalho pedagógico, mas tampouco podemos ignorar seu lugar ainda de referência - no direcionamento das atividades curriculares. Mesmo sob críticas severas e pertinentes a este papel indevidamente ocupado pelo livro didático, constatamos, por esse Brasil a fora, que é raro o registro de que ele não seja o que determina e condiciona a seleção de conteúdos e as estratégias de ensino. Ou seja, o livro didático, na quase totalidade da realidade escolar por nós observada, interfere decisivamente no que e no como ensinar em nossas escolas, e no que e como se aprende, ao se dirigir simultaneamente a dois tipos de leitores: o aluno e o professor.

Diante deste quadro, é grande nossa responsabilidade como autoras. A premissa com qual trabalhamos não considera o livro didático como o responsável pelos problemas do ensino nacional nem como a panacéia para esses problemas. Quando discutimos o hiato que separa o professor e a sala de aula da Educação Básica das pesquisas feitas sobre Ensino de Ciências, constatamos como pesquisadoras deste campo, ex-professoras da Educação Básica, formadoras de professores que vão atuar no ensino fundamental e médio e autoras de um material que ao contrário da maioria das publicações especializadas, chega efetivamente às mãos do professor - o livro didático podemos colaborar nesta aproximação academia-escola.

\section{A sexualidade nos currículos e livros didáticos}

É consenso no meio educacional que o currículo escolar não pode estar desvinculado da realidade dos alunos, tendo em vista que uma das funções da escola é a preparação para vida cidadã. No contexto desta discussão, entendemos que as questões relativas ao corpo, gênero, sexualidade e papéis sociais devem ser trazidas para sala de aula, dado o impacto que provocam na vida dos alunos. Consideramos que estas questões devem ser tratadas sob uma abordagem plural, transversal e interdisciplinar. Contudo, sabemos que, freqüentemente, é atribuída ao professor de Ciências a tarefa de iniciar ou até mesmo se responsabilizar por conduzir as discussões acerca da sexualidade. Por avaliar que é importante, atentamos para não reduzir o tratamento dado 
a estas questões a um enfoque meramente biológico, que possa reforçar estereótipos e preconceitos, e buscamos, sempre que possível, propor interface com outras disciplinas para enriquecer as atividades desenvolvidas em torno do tema sexualidade humana. Muitas vezes, porém, as angústias e tabus acerca da sexualidade estão baseadas no desconhecimento da anatomia e da fisiologia do próprio corpo. Daí a importância de criar condições para que os professores possam conversar com os alunos, levando-os a expressar suas crenças e seus mitos em relação ao corpo e à sexualidade como ponto de partida para o estudo dos aspectos biológicos do sexo. Pois sabemos que os alunos podem ficar inseguros quando vivenciam as modificações biológicas da puberdade e adolescência.

A relevância do tema no currículo é tal, que justificou a inserção da orientação sexual como tema transversal no Ensino Fundamental, de acordo com os Parâmetros Curriculares Nacionais propostos pelo Ministério da Educação, nos anos 1990. Neste documento, destaca-se que a sexualidade se expressa de diferentes formas nas escolas: por conceitos e idéias, tabus, preconceitos, estereótipos, comportamentos e atitudes tanto dos alunos como de professores:

\begin{abstract}
A sexualidade envolve pessoas e, conseqüentemente, sentimentos, que precisam ser percebidos e respeitados. Envolve também crenças e valores, ocorre em um determinado contexto sociocultural e histórico, que tem papel determinante nos comportamentos. Nada disso pode ser ignorado quando se debate a sexualidade com os jovens. O papel de problematizador e orientador do debate, que cabe ao educador, é essencial para que os adolescentes aprendam a refletir e tomar decisões coerentes com seus valores, no que diz respeito à sua própria sexualidade, ao outro e ao coletivo, conscientes de sua inserção em uma sociedade que incorpora a diversidade." 1
\end{abstract}

Silva e Megid Neto (2006) atentam que expressões de preconceito, homofobia, desinformação ou desigualdade nas relações de gênero fazem com que a experiência da sexualidade possa converter-se em situações de risco à saúde dos adolescentes, daí a importância de adoção por parte das escolas de um conjunto de medidas de informação e promoção da saúde, bem como formas de intervenção que superem a fragmentação da

\footnotetext{
1 BRASIL. Secretaria de Educação Fundamental. Parâmetros Curriculares Nacionais: terceiro e quarto ciclos: apresentação dos temas transversais. Brasília: MEC-SEF, 1998. Volume: Orientação Sexual
} 
questão e o componente moral do debate. Ainda no campo de estudos sobre sexualidade, currículo e livro didático destacamos a pesquisa realizada por Imperatori et al (2008), que teve o objetivo de analisar a linguagem sobre diversidade sexual dos livros didáticos recomendados pelo Ministério da Educação/MEC e dos livros didáticos em circulação sobre orientação sexual e ensino religioso para crianças e adolescentes de escolas públicas do ensino fundamental e médio. Os autores deste estudo lembram que recentemente, diversos trabalhos têm mostrado como a homofobia se manifesta no ambiente escolar (KNAUT, TERTO JR e POCAHY, 2006; UNESCO, 2004; CASTRO et al, 2004 apud IMPERATORI et al, 2008). Nestes estudos reafirmam o papel do professor em sala de aula na promoção e valorização da diversidade sexual combatendo a homofobia e o preconceito em suas diversas esferas. Nesse contexto, os pesquisadores lembram que os livros didáticos utilizados em sala de aula ganham importância no que tange ao auxílio para o combate à discriminação, preconceito e homofobia nas escolas e na sociedade como um todo. Na análise destes pesquisadores, embora a avaliação dos livros didáticos realizada sistematicamente pelo MEC seja eficaz na exclusão de linguagem homofóbica, o silêncio e a naturalização dos papéis de gênero nestes materiais podem contribuir para a manutenção dos valores homofóbicos na sociedade quando reforçam padrões "heteronormativos". Além disso, esta omissão na abordagem da diversidade sexual nos livros acaba por atribuir ao professor a responsabilidade de trazer o tema à sala de aula.

Voltando na história, é interessante lembrar que na década de 1960 algumas escolas brasileiras mais progressistas tentaram implantar a orientação sexual nos seus programas. No Rio de Janeiro, tivemos os colégios José Bonifácio e André Maurois, este último atendendo ao pedido dos próprios alunos. A partir do golpe de 1964, entretanto, sob argumentos de imoralidade e inutilidade, o Governo, através de suas Secretarias de Educação, condenou e proibiu os projetos de orientação sexual. Em 1968, a Comissão de Moral e Civismo do Ministério da Educação e Cultura rejeitou o projeto de lei apresentado pela então deputada do PMDB Júlia Steibruck, que propunha a implantação da orientação sexual em todas as escolas do Brasil. No parecer da Comissão que rejeitou o projeto, representantes da Igreja e das Forças Armadas argumentaram que a orientação sexual teria efeitos desastrosos, "contaminando" as escolas com escândalos, e que essa orientação deveria ser substituída por "educação da pureza". Segundo o general Moacir Araújo Lopes, da Comissão, "não se abre à força 
um botão de rosas e, sobretudo, com as mãos sujas" 2. O discurso conservador de 1964, e em especial do pós-1968, não impediu as mudanças nos comportamentos em geral e, em especial, sexual da sociedade, mas contribuiu significativamente para abortar as primeiras tentativas de orientação sexual. Quatro décadas após, a resistência à implantação de tais programas continua a existir.

Falar do corpo e da sexualidade é tão "delicado" que muitas vezes abordagens mal feitas podem acabar por reforçar tabus e preconceitos e disseminar informações errôneas. Pode-se tomar como exemplo os anúncios veiculados na década de 1990 como parte da campanha do Ministério da Saúde em prevenção à AIDS. Em um deles era mostrado uma mulher tomando banho e afirmando que "se cuida", como se higiene pessoal fosse medida profilática eficiente contra a AIDS. A abordagem superficial e até hipócrita do tema pode ser mais perigosa que o total silêncio. Felizmente, hoje, as campanhas feitas pelo Ministério da Saúde avançaram muito neste sentido e são referências positivas para outros países.

Observa-se que sobram informações aos adolescentes e crianças, vindas da TV, revistas, amigos, aulas de Ciências, etc. A questão é como essas mensagens chegam até eles. Em suas cabeças, misturam-se os ingredientes de uma sociedade erotizada, de culto ao corpo, com a incapacidade de reconhecer o próprio corpo em uma embalagem de absorventes ou na descrição da bula de um remédio. O conhecimento relativo à sexualidade e ao corpo fica restrito às aulas de Ciências. Como então fazer chegar recursos aos professores para que se supere a prática, que sabemos existir, do professor que com ar solene discorre sobre um tal aparelho reprodutor? Enquanto na escola, ou pelo menos na maioria dos livros de Ciências, a questão da sexualidade é ignorada ou abordada superficialmente, no dia-a-dia percebemos uma verdadeira erotização da infância. Os mesmos pais e professores, que muitas vezes se mostram contrários que se discuta, se fale do corpo e da sexualidade na escola, ficam orgulhosos quando seus "pimpolhos" em festas infantis ou adolescentes executam coreografias como "dança do créu”, “dança da garrafa", "do pirulito", "do tchan" e similares. E o grande número de grávidas adolescentes? Quantas tiveram acesso à informação sobre contraceptivos? Talvez, a maioria. Vê-se, então, que só informação não basta. Outros fatores, como

2 Citado em: RIBEIRO, P. R. M. Educação sexual além da informação. São Paulo: EPU, 1990. Temas básicos de educação e ensino. 
medo, insegurança, baixa auto-estima, assimetrias de gênero nas negociações sobre direitos sexuais e reprodutivos devem ser considerados na análise desta questão e denotam a importância de relativizar generalizações no campo da sexualidade. Entendemos não ser tarefa da escola e dos professores terem respostas prontas para essas e outras questões. Contudo, o importante é abrir o canal de comunicação e oportunizar o debate, no que o livro didático tem um papel significativo. Essas e outras questões e reflexões estiveram presentes durante todo o processo de elaboração e revisão dos textos, seleção das imagens e atividades para a nossa proposta de livro didático.

\section{De que lugar estamos falando?}

Para estabelecer o diálogo calcado na parceria com os colegas professores, hoje, ocupando também o lugar de autoras de livros didáticos, percorremos uma longa trajetória. A primeira etapa desta trajetória aconteceu nas salas de aula, quando no papel de professoras, nos vimos diante do desafio da abordagem da sexualidade humana nas aulas de Ciências. Ao recorrer aos livros didáticos, entendendo-o como coadjuvante da ação pedagógica, alguns aspectos ali apresentados continham informações errôneas ou legitimavam crenças subjetivas ou posturas ideológicas em desacordo com os objetivos de nossa proposta de ensino e de educação.

Sempre nos incomodou a maneira como o corpo historicamente tem sido apresentado e, deste modo, estudado nos livros didáticos de Ciências. Programas de Saúde? Melhor seria chamá-los "programas de doença" diante das listas de enfermidades e agentes patogênicos apresentados. O tema sexualidade humana? Lá, quase ao término dos livros, onde, em geral, o professor nunca chegava durante o ano letivo, fala-se sobre aparelho reprodutor. Figuras? Apareciam, desde que em cortes transversais ou longitudinais. Difícil para o aluno era reconhecer-se nas estranhas figuras assexuadas. Ainda hoje, em muitos livros, as figuras humanas, quando aparecem "de corpo inteiro" não apresentam órgãos sexuais externos. Pênis e vaginas, em geral, só aparecem em cortes "estratégicos", expondo apenas sua anatomia interna. Quando "de costas", as figuras são mostradas nuas, mas de frente "ganham" uma providencial sunga ou calcinha. Com figuras humanas idealizadas, os livros acabam por reforçar o papel da mídia, que nos bombardeia com anúncios que hiper valorizam a aparência física e 
acabam por determinar padrões estéticos. Padrões que são buscados febrilmente nas academias de ginástica, no uso de anabolizantes e se refletem nos consultórios médicos em busca de "reparos" ou, em alguns casos, de tratamento para distúrbios como bulimia e anorexia. Com seu corpo ainda desengonçado e com acne, o adolescente se depara, nos livros didáticos, com figuras e modelos "perfeitos", bem torneados e com dentes corretos e, então, não se reconhece como tal.

Esta primeira etapa somou-se à tarefa de coordenação de curso com o desafio do compromisso de dar novos significados, no projeto pedagógico das escolas, ao tema da sexualidade numa abordagem que veiculasse questionamentos para além dos saberes científicos e atendessem aos objetivos educacionais em relação à saúde e à ética, considerando o contexto sócio-cultural nosso e dos alunos. Concomitantemente a esta etapa, registramos a experiência de trabalhar em projetos de formação continuada de professores. Com os colegas de militância em sala de aula dividíamos as dúvidas, os acertos e erros na busca de conseguir, na prática de sala de aula, a interação entre o saber que os alunos trazem relativos ao corpo e sua sexualidade, o saber científico e, sob severas críticas, o veiculado pelo livro didático. Neste contexto, ressaltando a importância da mediação própria da ação pedagógica do professor em relação aos materiais didáticos, em especial, ao livro didático. Esta etapa, regida pelo saber empírico do fazer cotidiano, representou os passos iniciais para o trabalho acadêmico sistematizado. Os estudos, os debates, as reflexões e trabalhos resultaram na dissertação de mestrado (WALDHELM, 1998), que discute, à luz das contribuições de Michel Foucault e Félix Guattari, a produção sócio-política do corpo nos livros didáticos de ciências. Mais adiante, reflexões e estudos acadêmicos foram complementados com uma tese de doutorado (WALDHELM, 2007), na qual o foco foi o papel do professor de ciências na escolha profissional de cientistas. A aquisição do acervo de conhecimento acadêmico é inegavelmente importante, nesta trajetória. Contudo é na militância da prática da sala de aula do ensino fundamental, médio e superior que, prioritariamente, fundamentamos a proposta de produzir, com outros colegas, uma coleção de livros didáticos. 


\section{Desvelando os bastidores}

Reuniões, encontros e desencontros, debates e discussões, desistências... Acordos, desacordos, acordos. Horas... muitas horas de trabalho e reflexão. Daí resultou a proposta de se elaborar a coleção de livros didáticos. ${ }^{3}$

Considerando ser o livro didático, um dos materiais pedagógicos de maior relevância na escola, o ponto de referência no processo de ensino e, enquanto instrumento pedagógico auxiliar da aprendizagem, pois é através dele que o aluno, prioritariamente, vai aprender, a equipe de professores-autores optou por elaborar um material que tinha como proposta:

- corresponder aos padrões do conhecimento socialmente reconhecido com o compromisso de lhes dar novos significados ao veicular questionamentos a saberes superados cientificamente;

- satisfazer as expectativas dos leitores escolares (alunos, professores, familiares) e às diretrizes do sistema educacional vigente;

- respeitar os princípios éticos que alicerçam a nossa sociedade;

- reconhecer a autonomia e competência dos professores e a possibilidade de diferentes leituras de nossos textos.

Algumas discussões ocuparam com frequiência as pautas das reuniões, dentre outras: a compreensão sócio-histórica da Ciência, a educação científica escolar, a função social da escola e a relação entre o saber científico e a cultura etc. que nos levaram a autores que afirmam que, além de produzir conhecimento, a instituição escola é autônoma na manutenção, na produção ou reformulação de cultura. Lemos Chervel (1999 p.184) que escreve "o sistema escolar (...) forma não somente os indivíduos, mas também uma cultura que vem por vez penetrar, moldar, modificar a cultura da sociedade global."

Nesta perspectiva, avaliamos que o esforço a ser despendido na elaboração de uma proposta ambiciosa como a de nos tornarmos professoras/autoras de livro didático

\footnotetext{
3 Escrevemos em co-autoria com Ana Maria Pereira a Coleção Ciências-Pereira Santana e Waldhelm ( 1999) e nas coleções Passaporte para Ciências (2006) e Perspectiva Ciências (2009) tivemos também os colegas Ana Paula Bemfeito e Carlos Eduardo Cogo Pinto como co-autores nos volumes de nono ano . Todas estas coleções foram publicadas pela Editora do Brasil sob a coordenação editorial de Regina Lúcia Faria Miranda. 
valeria o investimento de tempo, estudos, pesquisas e da árdua tarefa de escrever, escrever e re-escrever.

Os desafios se apresentavam de forma, diríamos rotineira, tal era sua frequência. As nossas "marcas" era um deles. Como superar "marcas" ideológicas, conceituais ou pré-conceituais oriundas de nossa formação? Foram exigidas leituras críticas criteriosas por cada elemento da equipe, pela coordenadora editorial e por especialistas a cada etapa da produção dos textos, da seleção das imagens e elaboração de exercícios. Uma tarefa contínua para, além de evitar a ocorrência de erros conceituais e metodológicos, garantir a não veiculação de preconceitos socioculturais em nosso discurso. O maior "nó" a ser desatado, porém, foi assumir que se optássemos em escrever para o que em nosso grupo passamos a denominar "vaidade acadêmica', faríamos uma obra que estaria consoante ao que defendem os pesquisadores em ensino de ciências, mas provavelmente não atenderia às reais expectativas e necessidades dos professores que utilizam os livros. Sem hipocrisia, não vimos sentido em produzir coleções para enfeitar bibliotecas, mas sim em contribuir concretamente com um material que fosse parceiro no trabalho cotidiano do professor de ciências e obviamente, ter retorno financeiro com esta produção.

Nossa experiência, advinda de anos usando livro didático em sala de aula, nos informava sobre nossos possíveis leitores. Sabíamos que um leitor específico - com sua historicidade, com suas experiências e expectativas, em um dado momento - produz novos significados a partir do estímulo de uma forma simbólica como: textos escritos, imagens etc. Tínhamos consciência que o livro didático se enquadra na categoria de formas simbólicas que podem ser ideológicas, mas também, se abrem à possibilidades de interpretações. A necessidade de aprofundar este conhecimento nos levou à leitura de Thompson (1995) que apresenta os cincos aspectos das formas simbólicas, e assim, a partir dessa referência, avaliarmos a obra que estávamos produzindo:

- aspecto intencional - a forma simbólica tem intenção de dizer algo, mesmo que sua percepção não se dê de forma direta e clara;

- aspecto convencional - as formas simbólicas têm convenções que permitem sua transmissão. Por exemplo: as normas da língua, as regras para a publicação etc.; 
- aspecto institucional - a produção e transmissão das formas simbólicas seguem estruturas, convencionadas por determinada comunidade, e que servem para a comunicação (aspecto intencional). Por exemplo: a disposição gráfica dos textos, gráficos e imagens (que realçam certos aspectos, assim como as sombras em pinturas);

- aspecto referencial - reforça a intenção de dizer algo a partir do referencial real e/ou da imagem que o leitor tem sobre esse referencial que produzirá significação à forma simbólica;

- aspecto contextual - as formas simbólicas são estruturadas em um determinado contexto sócio-histórico- espacial, assim como todo autor e leitor.

Uma das concessões mais difíceis que fizemos foi abrir mão da proposta que tínhamos aplicado em nossa primeira coleção, quando tentamos fugir da sequência encontrada historicamente nos currículos de ciências. Embora a maior transgressão tenha sido elaborar um volume para a antiga oitava série onde os fenômenos físicos e químicos eram abordados de modo integrado, fazendo sempre que possível a interface com biologia e outras disciplinas, dentro dos outros volumes também queríamos ousar. Assim, por exemplo, embora fazendo uma abordagem evolutiva, começamos o estudo dos seres vivos pelo ambiente e sua diversidade, passamos pelas plantas e iniciamos a discussão dos outros reinos, pelos mamíferos conhecidos por nossos alunos (cachorro, gato etc.). Era nossa intenção partir do que era familiar, visível a olho nu, macroscópico, antes de mergulhar no mundo "invisível" dos vírus, por exemplo. Na estruturação das novas coleções que escrevemos, após ouvir professores de todas as regiões do Brasil principalmente em atividades de formação continuada que mediamos, resolvemos seguir uma sequiência de conteúdos considerada tradicional nos currículos de Ciências. A opção por essa organização se justificou pelo desejo de apresentar um material didático o mais próximo possível da realidade da maioria das escolas brasileiras. Refletimos que ser parceiros do professor implica respeitar aquilo que a maioria gosta de fazer, propondo é claro, alternativas e inovações, sem tirar, contudo, o "chão", a referência deste professor. Buscamos amenizar a fragmentação destes conteúdos, sempre que possível retomando-os em outros níveis de profundidade nos diferentes volumes. Além disso, contamos com a autonomia e criatividade do professor para reorganizar os temas 
propostos de maneira mais adequada e significativa de modo a atingir os objetivos do seu planejamento.

Cada tema abordado e cada conteúdo selecionado mereceram cuidados próprios. Pesquisas, estudos e a determinação de que a elaboração do esboço geral e básico seria incumbência do parceiro da equipe que apresentasse maior afinidade com o tema foi alguns desses cuidados. Cada volume das coleções foi alvo de atenção, pois os temas a serem abordados tinham desafios específicos. Falaremos aqui do volume três, que incluiu a unidade sobre sexualidade humana. Ao abordar o estudo do corpo humano, embora tenhamos dedicado capítulos em separado para os diferentes sistemas, buscamos apresentar as relações entre eles e mostramos exemplos de sua ação integrada, reforçando a importância de cada um na homeostase orgânica. Sempre que possível, retomamos conceitos trabalhados nos volumes anteriores, lembrando ao aluno as características dos seres humanos comuns a outros animais e a relação de nossa espécie com o ambiente e demais seres vivos. Do mesmo modo, procuramos associar fotografias com esquemas, buscando agregar valor didático sem deixar de retratar a realidade. Consideramos as imagens particularmente importantes quando estudamos seres ou estruturas visíveis somente ao microscópio. Chamamos a atenção para a questão das proporções e cores fantasia, a fim de não reforçar no aluno representações mentais equivocadas. As legendas pretendem agregar valor informativo, além de dados descritivos. Evitamos ainda analogias que reforcem a visão mecanicista - a qual procura representar o corpo como "máquina" que requer "combustível" - e outras similares. Destacamos as questões relativas à saúde e sexualidade, ressaltando a necessidade de conhecer o corpo e cuidar dele, para se ter uma vida mais prazerosa. Na Unidade relativa à sexualidade, discutimos o tema sob uma perspectiva mais ampla que o simples recorte anátomo-fisiológico. Ao longo do volume, os conteúdos relativos à saúde estão articulados a vários contextos, em suas dimensões individuais, coletiva e global. Em relação à etnia, concordamos que o "silenciamento" no trato das questões étnico-culturais, no livro didático pode colaborar no cerceamento de referenciais positivas necessários à formação da auto-estima na criança não-branca e reforçar preconceitos. Assim, tivemos o cuidado especial na seleção de imagens e na proposta de atividades, seja na discussão da sexualidade e dos papéis sexuais/sociais, na desconstrução do conceito ainda difundido de "raças humanas", na voz dada a mulheres cientistas, bem como nas fotos que retratam situações não estereotipadas (mulheres 
trabalhadoras em indústria e ciência, homens cuidando de filhos etc.) dentre outros aspectos. Tampouco foram admitidas fotos de adolescentes do tipo "modelos ou atores de novelas". Os adolescentes, bem como todas as pessoas retratadas em nossos livros são "gente com cara de gente". Foi nossa intenção colaborar na construção de currículos e práticas pedagógicas que expressem a riqueza das identidades e da diversidade étnico-cultural presente na escola e na sociedade.

No âmbito desta discussão citamos o estudo de Moro (2001) que analisou a questão de gênero no ensino de ciências com foco na prática e discurso de professores. Ao observar aulas de ciências e entrevistar professores, a pesquisadora constatou que docentes do ensino básico em sua maioria desconhecem a problemática da desigualdade de gênero e reproduzem estereótipos sexuais, não pela intencionalidade, mas pela desinformação. Os professores que foram entrevistados enfatizaram que eram mais comuns em meninas, características atribuídas ao "bom aluno", tais como passividade e obediência. A pesquisadora questiona em seu trabalho o quanto esse tipo de comportamento favorece efetivamente o aprendizado de ciências. Já o estudo de GOMES et al (2004) que analisa a situação das escolhas de adolescentes brasileiras em relação às profissões que demandam conhecimentos em ciências, matemáticos e tecnologias computacionais, denuncia que as matrículas do ensino superior nas áreas do conhecimento ligadas às ciências e tecnologias indicam que o gênero feminino está subrepresentado. Por este motivo, achamos importante e necessário não ignorar as questões de gênero em nossos livros, tanto no discurso, quanto nas representações, ilustrações e fotos utilizadas.

Neste volume, num total de seis unidades, optamos em abordar a sexualidade na terceira Unidade. Queríamos evitar que este tema fosse relegado a segundo plano caso ficasse ao fim do livro. Para não limitar a abordagem a biologização, embora no contexto de um livro de ciências, iniciamos a Unidade discutindo a dimensão plural da sexualidade, os tabus, os papéis sexuais e sociais, estereótipos, o papel da mídia etc. O texto foi objeto de cuidadosa análise, pois não queríamos produzir nem reforçar subjetividades ${ }^{4}$ hegemônicas que levassem a preconceitos e discriminação por gênero,

4 Por produção de subjetividades entendemos os diferentes modos de sentir, pensar, perceber e agir sobre o mundo produzidos histórica e socialmente. Esta concepção baseia-se nas contribuições de GUATTARI, F. e ROLNIK, S. Micropolítica: cartografias do desejo. Rio de Janeiro: Vozes, 1986. 
etnia, orientação sexual etc. Em diversos momentos, colocamos bilhetes dirigidos ao professor sinalizando para a importância em debater determinados tópicos e atentar para atitudes preconceituosas. Ao abordar as características anatômicas femininas e masculinas, as ilustrações produzidas não se limitam a mostrar cortes longitudinais ou transversais ou apenas o interior dos órgãos. São oferecidas também representações de corpos inteiros e com as estruturas externas visíveis, a fim de que o aluno possa reconhecer seu próprio corpo na imagem apresentada no livro.

Esta opção nos causa problemas até hoje em várias escolas, em particular as confessionais. Houve instituições, nas quais embora professores manifestassem explicitamente o desejo de adotar nossas obras, a presença de imagens de vulvas e pênis foi motivo de proibição da adoção por parte de coordenação ou da direção. Em outras, o volume três foi o único não adotado. Poderíamos publicar um anedotário com as narrativas de fatos semelhantes ao da aluna, da antiga sétima série, que um dia foi vista desenhando roupas em todas as (poucas) figuras (parcialmente) nuas do livro didático que utilizávamos; ou o ocorrido em uma escola, cuja professora de ciências venceu a resistência da coordenadora e adotou a coleção, houve relato de uma mãe de aluna de treze anos que grampeou as páginas do nosso livro que continham figuras de vulvas, pênis, camisinha e similares. Registramos que a imagem da vulva causou mais espanto que as que retratavam pênis. Parece haver maior naturalidade no trato com a anatomia masculina. Não é à toa que a maioria das mulheres (e homens) refere-se à vulva como vagina. Em suas escolas, nos seus livros didáticos, possivelmente, só estudaram anatomia interna do corpo feminino.

A preocupação com a aceitação mercadológica da obra foi tal, que fomos convencidas pela Editora a reduzir (não aceitamos excluir!) na segunda edição as dimensões da ilustração da vulva. Embora contrariadas, entendemos que esta concessão permitirá a adoção do livro por professores que manifestaram este desejo e foram impedidos. No rol das concessões, também está a exclusão de uma atividade na qual sugeríamos às alunas que em casa observassem suas vulvas com ajuda de um espelho.

Cuidamos para não reforçar a 'pedagogia do terror', associando sexualidade à doença ou gravidez indesejada. Sem ignorar temas como contraceptivos, DSTsincluindo AIDS - masturbação e aborto. Destacamos a importância do cuidado com o corpo associando-o à promoção da saúde e à vivência prazerosa e responsável da sexualidade. 


\section{Compartilhando um desejo}

Embora parceiro no trabalho docente, entendemos que o livro didático nunca poderá prescindir da autonomia e criatividade do professor que o adota. Sua adoção será significativa se o material for empregado para apoiar situações de aprendizagem em que o aluno possa questionar, debater, levantar hipóteses, experimentar, investigar, buscar respostas e não simplesmente "consumir" informações prontas e acabadas. Nossa experiência docente nos mostra que no ensino de Ciências há espaço tanto para aula expositiva, quanto para a atividade experimental, demonstrações, trabalho individual e coletivo, projetos, debates e outras estratégias que enriquecem o ambiente de aprendizagem ao desenvolver e mobilizar nos alunos competências diversificadas. Cabe ao professor, no seu contexto pedagógico, de tempo, espaço e em face dos recursos disponíveis, selecionar as atividades que julgar mais oportunas e interessantes para a aprendizagem dos alunos, incrementando-as sempre que possível, para ampliar os limites que qualquer recurso didático - incluindo o livro - apresenta.

Não queremos, como alerta Foucault (1989), enquanto intelectuais, ser agentes da "consciência" e do discurso. Sabemos que fazemos parte de um sistema que barra, proíbe e invalida o saber das camadas populares, onde o poder polimorfo circula livremente. Esperamos, contudo, assumir, como sugere Silva (1995), o papel de intelectual educacional vulnerável, limitado, parcial, falível, mas participante coletivo do processo social. E neste sentido, consideramos que silenciar - nos discursos e práticas - no âmbito das questões relativas à sexualidade humana, tem implicações gravíssimas na formação de nossas crianças e jovens. Compartilhamos as idéias de Furlani (2008 p.129) que diz:

Independentemente do nível de ensino, a discussão da sexualidade não deve se privar de mostrar o quanto a vida humana é normatizada, significada e hierarquizada. A busca por uma sociedade de paz, de respeito e de convivência pacífica passa pelo reconhecimento da diversidade, qualquer que seja ela, como positiva. Questionar as muitas formas de preconceito e de exclusão social é papel de uma Escola que quer e que constrói uma sociedade menos sexista, menos racista, menos misógina e menos homofóbica - e isso começa na Educação Infantil.

Para finalizar esta conversa, lembramos do saudoso mestre Paulo Freire (apud SNYDERS 1993, p. 9) ao dizer que "a alegria na escola fortalece e estimula a alegria de 
viver". Segundo ele, se o tempo da escola tem se configurado como um tempo de enfado, em que o educador, a educadora e os educandos vivem os segundos, os minutos, os quartos de hora, à espera de que a monotonia termine, a fim de partirem risonhos para a vida que os espera lá fora, a tristeza experimentada na escola termina por deteriorar a alegria de viver. Deste modo, viver plenamente a alegria na escola significa mudá-la, significa lutar para incrementar, melhorar e aprofundar a mudança. Além do mais, lutar pela alegria na escola também é uma maneira de lutar pela mudança no mundo.

\section{Referências bibliográficas}

BORGES, O. ; GOMES, C. M. A. O Currículo de Ciências pode ajudar a desenvolver a inteligência dos alunos? In: I X Encontro Nacional de Pesquisa em Ensino de Física, Jaboticatubas - MG, 2004.

CASTRO, M. G.; ABRAMOVAY, M; SILVA, L.B. Juventudes e Sexualidade, Brasília: UNESCO, 2004.

CHERVEL, A. História das disciplinas escolares: reflexões sobre um campo de pesquisa. Teoria \& Educação, n.2, p. 177-229, 1990.

FOUCAULT, M. Microfísica do poder. 8a ed. Rio de Janeiro: Graal, 1989.

FRACALANZA, H.; MEGID NETO, J. (Org.). O livro didático de Ciências no Brasil. Campinas: Editora Komedi, 2006. 224p.

FURLANI, J. Mulheres só fazem amor com homens? A Educação Sexual e os relacionamentos entre pessoas do mesmo sexo- revista Pro-Posições (Unicamp), v. 19, p. 111-131, 2008.

IMPERATORI, T. ; SANTOS, W. R. ; LIONCO, T. ; DINIZ, D. . Qual diversidade sexual dos livros didáticos brasileiros? In: Seminário Internacional Fazendo Gênero 8 Corpo, Violência e Poder, 2008, Florianópolis. Anais do Seminário Internacional Fazendo Gênero 8. Florianópolis: Editora Mulheres, 2008.

MORO, C. C. A questão de gênero no ensino de Ciências. Chapecó: Argos, 2001.

SILVA, T. T. (org.). O sujeito da educação. Estudos Foucaultianos. 2a ed. Petrópolis: Vozes, 1995.

SILVA, R. C. P.; MEGID NETO, J. Formação de professores e educadores para abordagem educação sexual na escola: o que mostram as pesquisas. Ciência e Educação, São Paulo, v. 2, n.12. 2006: 185-197.

SNYDERS, G. Alunos felizes: reflexões sobre a alegria na escola a partir de textos literários. Rio de Janeiro: Paz e Terra, 1993. 
THOMPSON, J.B. Ideologia e Cultura Moderna: teoria social crítica na era dos meios de comunicação de massa. Petrópolis: Vozes, 1995.

WALDHELM, M.C.V. Produção sócio-política do corpo nos livros didáticos editados nas décadas de 60 e 90. Dissertação de Mestrado, Niterói, UFF, 1998.

Como aprendeu ciências na educação básica quem hoje produz ciência? O papel dos professores de ciências na trajetória acadêmica e profissional de pesquisadores da área de ciências naturais. Tese de Doutorado em EducaçãoPontifícia Universidade Católica do Rio de Janeiro, Rio de Janeiro, 2007. 